\title{
INFLUÊNCIA DO USO DA TERRA NOS PARÂMETROS DA QUALIDADE DAS ÁGUAS SUPERFICIAIS DO MONUMENTO DAS LAGOAS URBANAS DA CIDADE DE TRES LAGOAS/MS NO INVERNO DE 2019
}

\author{
Mário Marcio Geminiano ${ }^{1}$ \\ Andressa Soares ${ }^{2}$ \\ André Luiz Pinto ${ }^{3}$
}

Resumo: Objetiva-se avaliar as implicações do uso da terra, na qualidade das águas superficiais das três lagoas no município de Três Lagoas - MS, com auxílio de geotecnologia. Neste intuito, realizou-se o mapeamento do uso da terra da bacia, correlacionando com a qualidade físico química da água. Para a mensuração da qualidade das águas superficiais, utilizou-se do medidor multiparâmetro Horiba. Para o enquadramento das classes de qualidade das águas, empregou-se a Resolução 357 de 2005 do Conselho Nacional do Meio Ambiente - CONAMA adaptada por Pinto et al. (2009). Os resultados apontaram que a terceira lagoa apresenta maiores riscos de degradação, por estar inserida numa área completamente antropizada. Porém, a primeira e segunda lagoas, também sofrem com a poluição e assoreamento ocasionados por ações humanas. Portanto, verificou-se além da degradação das lagoas, a necessidade das APPs para a preservação de corpos hídricos, com a intenção de manter, sobretudo, as características biológicas e físicoquímicas naturais desses ecossistemas.

Palavras-chave: Análise. Qualidade da água. Lagoas.

\section{INFLUENCE OF LAND USE ON THE SURFACE WATER QUALITY PARAMETERS OF THE MONUMENT OF THE URBAN LAGOONS OF THE CITY OF TRES LAGOAS/MS IN THE WINTER OF 2019}

Abstract: In order to evaluate the implications of land use and land cover on the quality of surface waters of the three lagoons in the municipality of Três Lagoas - MS, geotechnologies were used to map the use and land cover of the basin, correlated with the physical chemical quality of its waters. To measure the quality of surface water, the multiparameter meter Horiba was used. For the framing of water quality classes, Resolution 357 of 2005 of the National Environmental Council - CONAMA was used, adapted by Pinto et al. (2009). The results showed that the third lagoon presents more risks of degradation, because it is inserted in a completely anthropized area. However, the first and second lagoons also suffer from pollution and silting caused by human actions. Therefore, in addition to the degradation of the lagoons, there was a need for the APPs for the preservation of water bodies, with the intention of maintaining, above all, the natural biological and physical-chemical characteristics of these ecosystems.

Keywords: Analysis. Water quality. Ponds.

\footnotetext{
1 Universidade Federal de Mato Grosso do Sul, Três Lagoas, Brasil, mario_marcio12@hotmail.com https://orcid.org/0000-0002-6151-8255

2 Universidade Federal de Mato Grosso do Sul, Campus de Três Lagoas, Três Lagoas, Brasil, andressasoares.br@gmail.com, https://orcid.org/0000-0001-5357-4911

3 Universidade Federal de Mato Grosso do Sul, Campus de Três Lagoas, Três Lagoas, Brasil, andrepintofontanetti@gmail.com, https://orcid.org/0000-0001-9455-0684
} 


\section{INFLUENCIA DEL USO DEL SUELO EN LOS PARÁMETROS DE CALIDAD DE LAS AGUAS SUPERFICIALES DEL MONUMENTO DE LAS LAGUNAS URBANAS DE LA CIUDAD DE TRES LAGUNAS/MS EN EL INVIERNO DE 2019}

Resumen: A fin de evaluar las aplicaciones del uso y cobertura de la tierra en la cualidad de las aguas superficiales de las tres lagunas del municipio de Três Lagoas - MS, fue utilizado las geotécnicas para hacer la mapeamiento del uso y cobertura de la tierra de la cuenca hidrográfica, correlacionada con la cualidad física y química de sus aguas. Para la mensuración de la cualidad de las aguas superficiales, utilizó se del medidor Horiba multiparámetro. Para lo encuadramiento de las categorías de cualidad de las aguas, empleó se la Resolución 357 de 2005 del Consejo Nacional del Medio Ambiente - CONAMA adoptado por Pinto et al. (2009). Los resultados apuntaron que la tercera laguna presenta más riesgos de degradación, por estar ubicada en una zona completamente antrópica. Sin embargo, la primera y la segunda laguna también han sufrido con la polución y encenagamiento ocasionadas por las acciones humanas. Por lo tanto, además de la degradación de las lagunas, era necesario que las APP para la preservación de los cuerpos de agua, con la intención de mantener, sobre todo, las características naturales biológicas y físicoquímicas de estos ecosistemas.

Palabras clave: Análisis.Cualidad de las aguas. Laguna.

\section{Introdução}

Esse trabalho é fruto de inquietações que surgiram na disciplina: Geotecnologias aplicadas ao planejamento e gestão de águas, ministrada no Programa de Pós-Graduação em Geografia na Universidade Federal de Mato Grosso do Sul, campus de Três Lagoas (PPGGEO/ UFMS/ CPTL). A presente pesquisa se refere a análise da qualidade da água de corpos hídricos, que no caso são lagoas, e sua relação com o uso da terra.

A relação entre a qualidade da água e o uso da terra é fator preponderante para os órgãos de planejamento ambiental e urbano de um munícipio. Um lago poluído pode ser um problema grave para o ecossistema, do mesmo e para os moradores da região que usufruem dessa água através do banho, pesca ou mesmo navegação. Portanto, saber qual a origem e nível de contaminação existentes nele, e acima de tudo como solucionar o problema, passa a ser tarefa imprescindível.

No meio acadêmico, diversos trabalhos abordam a análise da qualidade da água relacionada ao uso/ cobertura da terra. Nesse ponto, um aliado interessante dos pesquisadores são as Geotecnologias, ferramentas capazes de coletar, organizar, processar e espacializar os dados. Os dados são informações 
alfanuméricas que somados ao geoprocessamento irão se tornar uma informação espacial georreferenciada.

O recorte espacial alvo de estudo é um complexo de três lagoas no município de Três Lagoas-MS. Para a melhor compreensão desse recorte, foi necessário analisar a Bacia Hidrográfica do Córrego da Onça - BHCO como um todo. A Bacia Hidrográfica do Córrego da Onça que abrange grande parte do perímetro urbano de Três Lagoas-MS teve papel importante no abastecimento urbano de água da cidade no passado. Porém, seu principal córrego que é o Córrego da Onça, atualmente encontra-se extremamente degradado.

Para a mensuração dos parâmetros físico-químicos da qualidade das águas superficiais da bacia foi utilizado o analisador multiparâmetro Horiba, útil na determinação do grau de contaminação do corpo hídrico e no seu enquadramento perante a resolução do Conselho Nacional do Meio Ambiente - CONAMA no. 357 de 2005.

Para a fundamentação teórica buscou-se referências bibliográficas direcionadas ao estudo das Bacias Hidrográficas, Análises da qualidade da Água, Geoprocessamento e Geotecnologias. Para o tema Bacia Hidrográfica, pautou-se em Braz (2017), Christofoletti (1980) e na Agência Nacional das Águas - ANA, entre outras fontes. Em se tratando de Análise da qualidade da Água em Bacias Hidrográficas, pautou-se em Souza \& Gastaldini (2014) e Gloria, Horn e Hilgemann (2017), entre outros. Em relação ao Uso da Terra e sua Influência na Qualidade da Água, pautou-se no Manual Técnico de Uso da Terra ( $2^{\circ}$ edição) do Instituto Brasileiro de Geografia e Estatísticas - IBGE e em Filho, Dutra e Ceruti (2012). Para a discussão sobre Geoprocessamento e Geotecnologias aplicados a qualidade da água, utilizou-se Fitz (2008) e Filho et al. (2016).

\section{Caracterização da área de estudo}

As três lagoas, localizadas no município de Três Lagoas no estado de Mato Grosso do Sul, estão inseridas na Bacia Hidrográfica do Córrego da Onça, no perímetro urbano do município.

A Bacia Hidrográfica do Córrego da Onça está situada entre as coordenadas

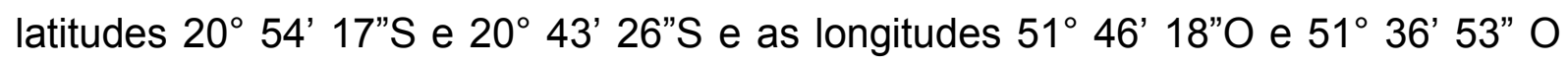
(SOUZA et al. 2018). No Mapa 1, pode-se observar a localização da Bacia Hidrográfica do Córrego da Onça - BHCO, no município e na cidade de Três Lagoas. 
Mapa 1. Localização da Bacia Hidrográfica do Córrego da Onça no município de Três Lagoas

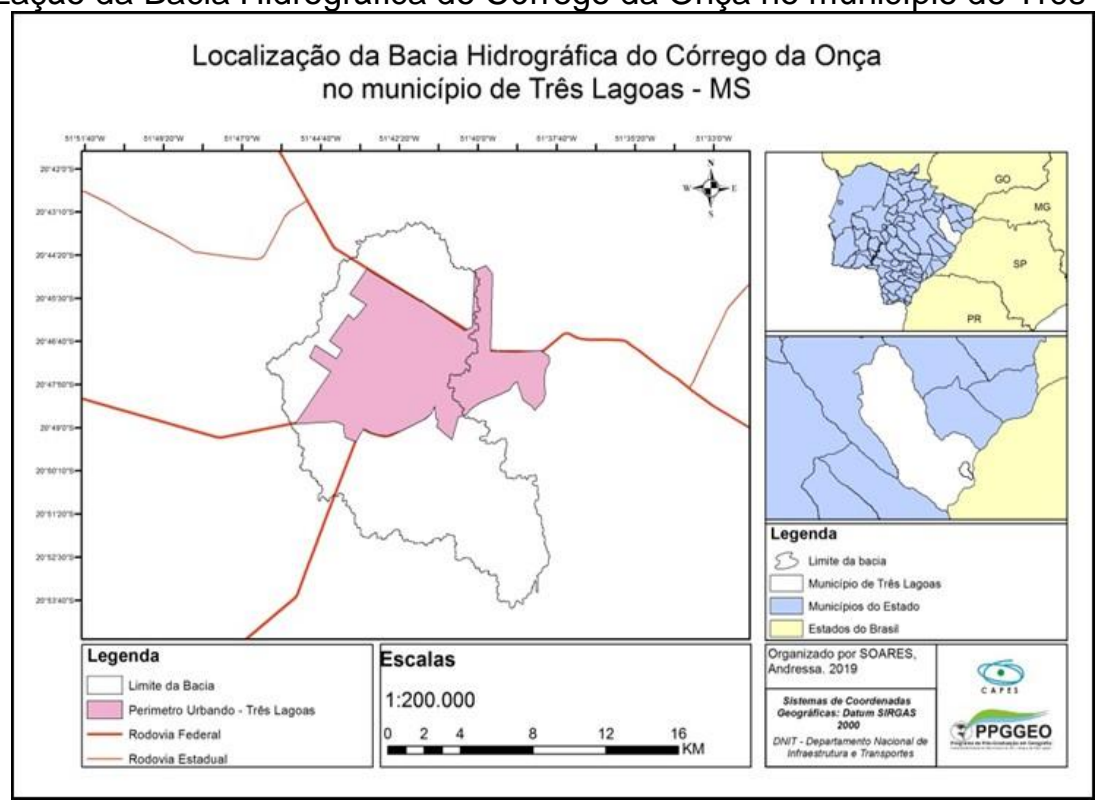

Fonte: Dos autores, 2019.

Devido a sua importância histórica e do seu encanto natural, as três lagoas fazem parte do cartão postal do município e atraem os moradores para momentos de lazer, contemplação da natureza e prática de esportes. Foram oficialmente tombadas, a partir do Decreto 188/2016, como Unidade de Conservação, denominada de Monumento Natural das Lagoas.

Mapa 2. Mapa de Localização das três lagoas

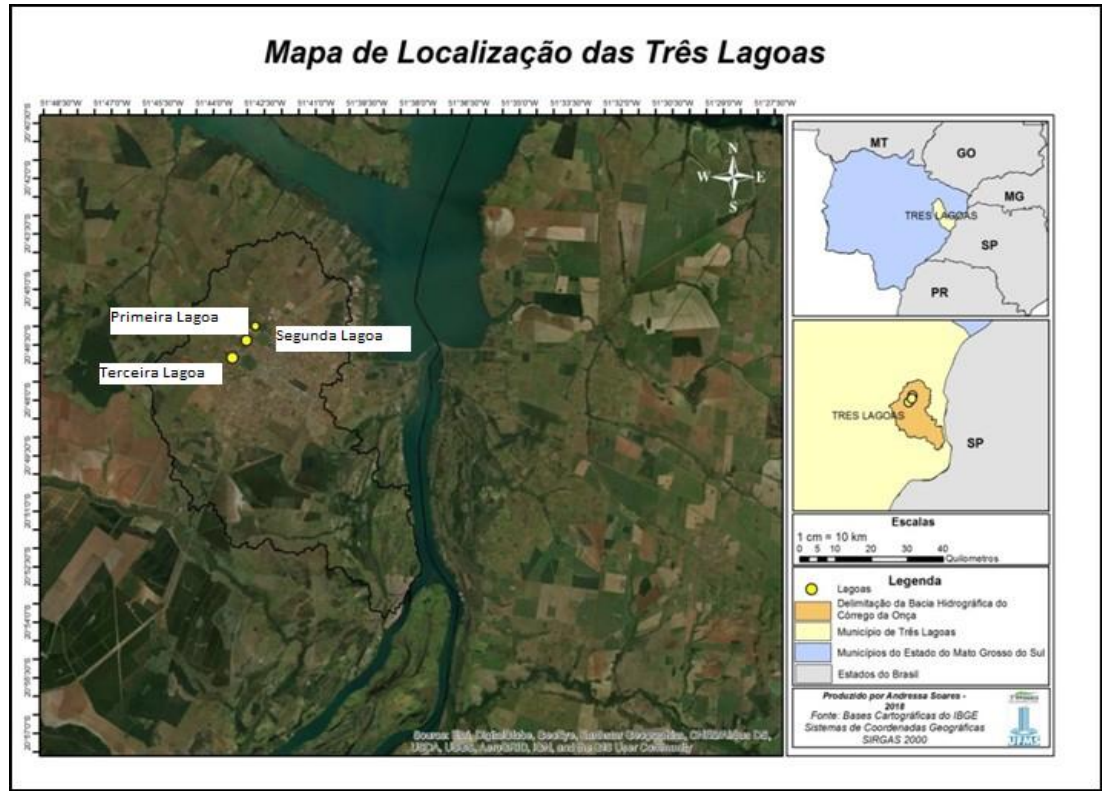

Fonte: Dos autores, 2019. 
Cada uma das lagoas apresenta diferentes características e são utilizadas de diferentes formas pelos moradores da região, a saber: Primeira e segunda lagoas: pesca amadora, e terceira lagoa: práticas de esporte e lazer. A constatação foi feita durante a visita às lagoas.

Em Três Lagoas, existe uma Unidade de Conservação - UC do tipo Proteção Integral, denominada de Monumento Natural das Lagoas que foi criada em 2016, por meio do Decreto 188/2016 de 13/12/2016. O monumento envolve um complexo de três lagoas com uma área total de $1,17 \mathrm{Km}^{2}$, que constituem um rico patrimônio ecológico e biológico do município, sendo de responsabilidade da esfera municipal a implantação de seu plano de manejo.

Segundo o Ministério do Meio Ambiente as Unidades de Conservação - UC, são espaços territoriais, que incluem os recursos ambientais, destinados a guardar amostras de diferentes espécies da fauna e flora, para a preservação dos mesmos.

Até os dias atuais, essa unidade de conservação não possui plano de manejo, porém possui um Conselho Gestor e é classificada pelo Sistema Nacional de Unidades de Conservação - SNUC como uma Área de Proteção Íntegral. Os biomas que abrangem essa UC são Cerrado e Mata Atlântica. No Mapa 2 pode-se observar a localização das três lagoas, no interor da bacia.

O Sistema Nacional de Unidades de Conservação da Natureza - SNUC, instituído pela Lei oㅜ 9.985, de 18 de julho de 2000, possibilita uma organização e visão das UC. Além disso, o SNUC regulamenta a participação da sociedade nas UC.

As UC são divididas em dois grupos distintos: Unidades de Proteção Integral, nas quais é permitida apenas o uso indireto dos recursos naturais. Exemplos de atividades desenvolvidas nessas unidades são turismo ecológico e pesquisa cientifíca, ou seja, são atividades que não prejudicam o meio ambiente. $O$ outro grupo são as Unidades de Uso Sustentável, que visam conciliar conservação da natureza e uso sustentável dos recursos. Nessas unidades são permitidas atividades de coleta, como por exemplo, a pesca, desde que não afete o tempo natural dos processos biológicos e ecológicos da área.

\section{Primeira Lagoa}

A primeira lagoa (Figura 1), conhecida também como "lagoa menor", possui no seu entorno vegetação arbustiva, com presença de árvores, e muita pastagem. 
Há presença de gado nas pastagens próximas às margens da lagoa. Há poucas residências próximo ao corpo hídrico. No entanto, há diversos entulhos de construção provavelmente descartados indevidamente por moradores.

Além disso, lixo doméstico, tais como latinhas de refrigerante, sacolas de plástico, também foram encontrados no local. É uma lagoa muito utilizada para a atividade de pesca. Durante a saída a campo (já mencionada anteriormente), observou-se alguns apetrechos para a pesca amadora, como redes, próximas a margem da lagoa.

Figura 1 - Primeira Lagoa

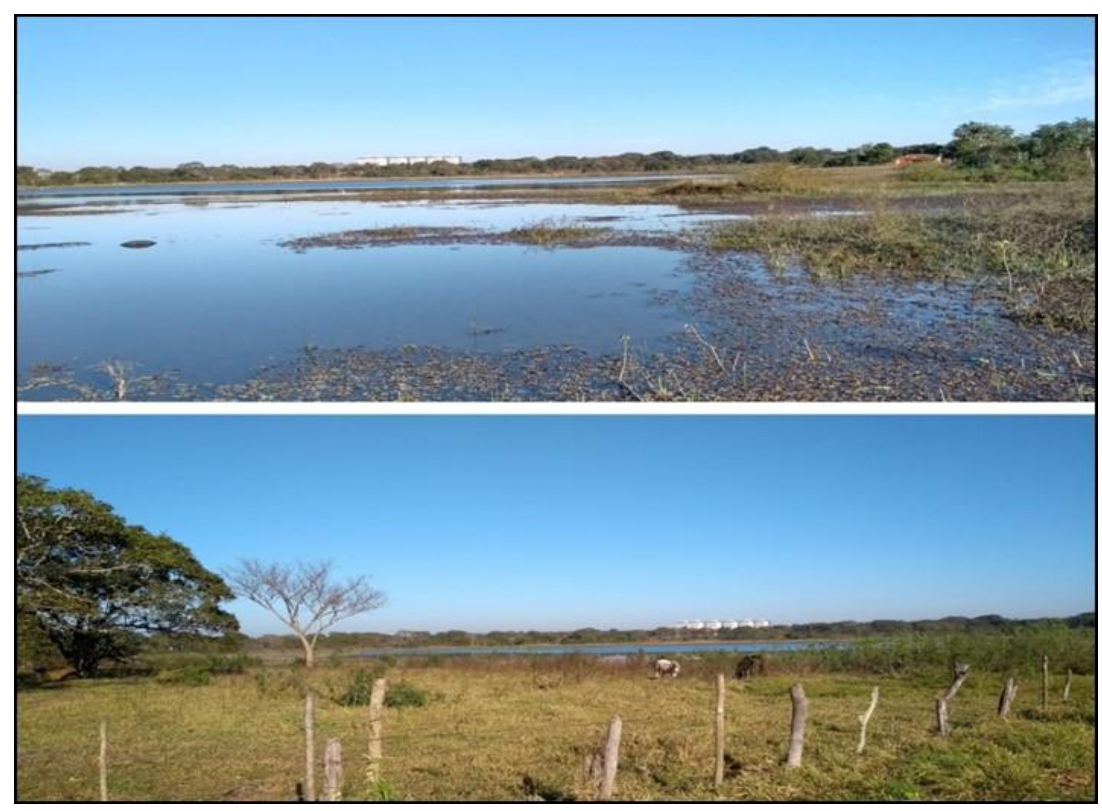

Fonte: Dos autores, 2019.

Anteriormente, a lagoa fazia parte de uma Área de Preservação Permanente - APP, mas após o Decreto 188/2016 ela passou a ser classificada como uma Unidade de Conservação. Perto do local é possível observar uma placa que informa a existência de uma APP no local. Porém, como já mencionado, a partir de 13/12/2016, a área passou a constituir uma UC.

\section{Segunda Lagoa}

Essa lagoa é conhecida como "lagoa do meio" por estar localizada entre as duas outras lagoas do complexo. Como se encontra no perímetro urbano, sofre grande influência antrópica, por consequência está exposta a problemas ambientais, como descarte inadequado de resíduos. Durante a visita, observou-se uma instalação para drenagem interligada com a terceira lagoa, porém, nenhuma sinalização indicava o local. 
No lado esquerdo das margens da lagoa foi observado um pequeno lago que tambem é utilizado por moradores da região para pescas amadoras. Olarias (desativadas) fazem parte da paisagem dessa lagoa, e contribuem para a contaminação da mesma, através dos resíduos que adentram a lagoa, por meio do escoamento das chuvas.

A cobertura vegetal pode ser classificada como arbórea, arbustiva com pequenas áreas de pastagem. Observou-se a presença de gado nas áreas de pastagem, como mostra a Figura 2.

Figura 2 - Segunda Lagoa

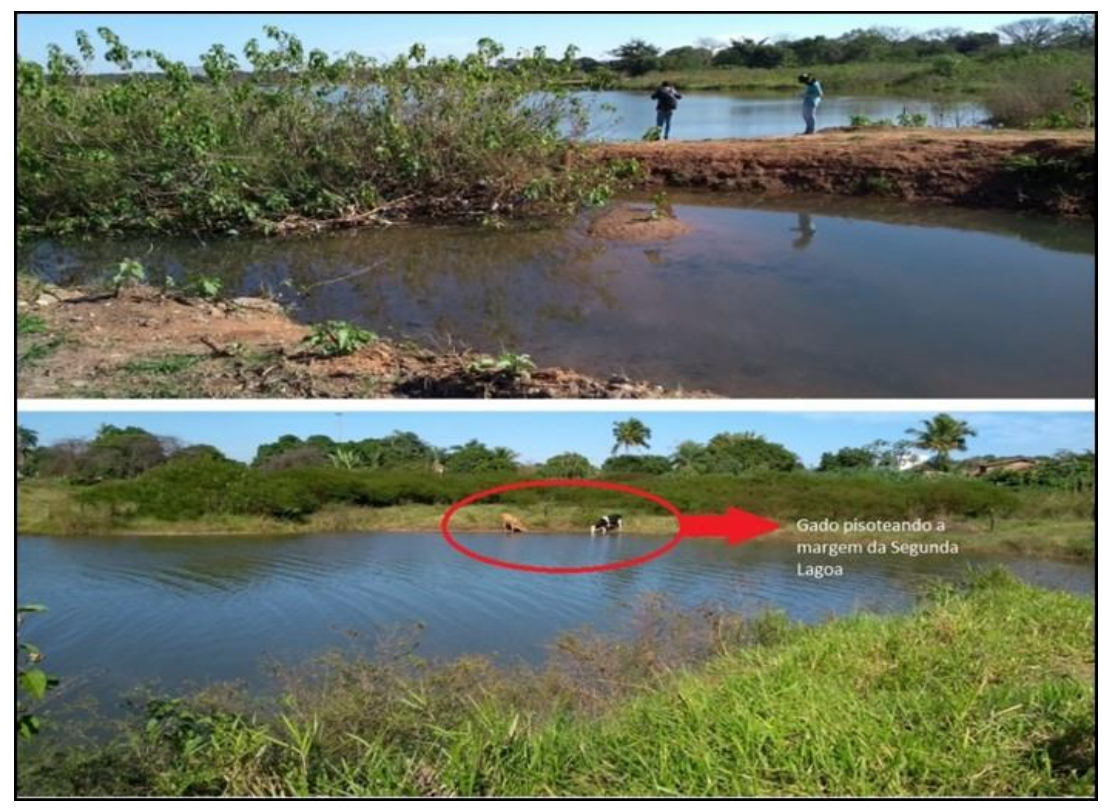

Fonte: Dos autores, 2019.

\section{Terceira Lagoa}

A terceira lagoa ou "lagoa maior" está diretamente ligada ao principal córrego da Bacia Hidrográfica do Córrego da Onça e está conectada a segunda lagoa, através de uma bomba de drenagem. A paisagem dessa lagoa se difere das demais nos seguintes pontos: predominância de diversas construções no seu entorno, e como consequência pouca vegetação nativa. Por outro lado, dentre a vegetação atual, as espécies encontradas são na sua maioria de palmeiras e gramíneas.

Nesta lagoa há presença de diferentes espécies de aves e animais, entre eles destacam-se araras e capivaras que são facilmente encontradas em quantidades significativas ao redor de toda a margem. Observa-se ainda a presença de jacarés e patos. No entanto é muito utilizada por moradores para momentos de lazer e prática 
de exercicios físicos. Em quetões estruturais a terceira lagoa é a unica que oferece estruturas e serviços voltados para população (Figura 3).

Figura 3 - Terceira Lagoa

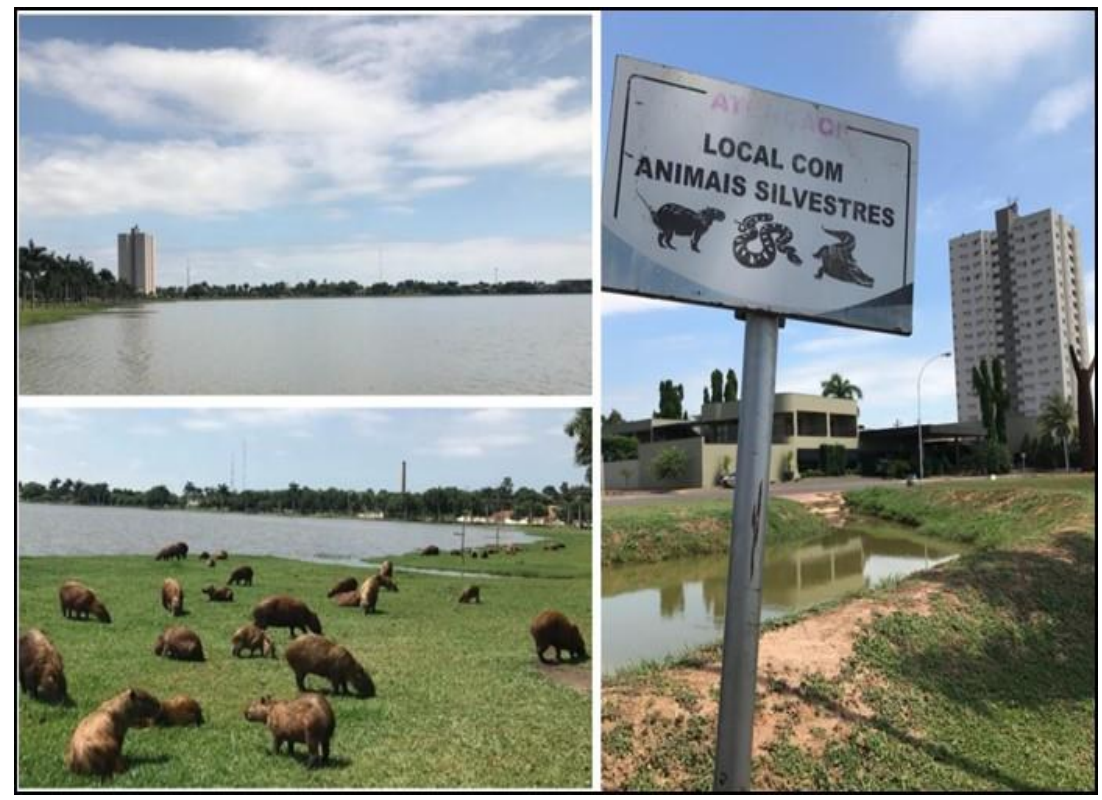

Fonte: Dos autores, 2019.

\section{Bacia Hidrográfica}

Ao se referir a uma cronologia de autores que já conceituaram bacia hidrográfica, Braz (2017, p. 40) escreve que os pioneiros foram Horton, em 1945 e Strahler, em 1952, e mais tarde, em 1969, Chorley amplia o entendimento sobre o assunto. Desde então, a bacia hidrográfica vem sendo tema de estudos de pesquisadores não só da Geografia, mas também das Ciências Exatas e Ciências Ambientais (BRAZ, 2017, p.40).

Existem diversas definições sobre o conceito, porém, boa parte delas chegam há um mesmo consenso, de que, bacia hidrográfica é uma área delimitada topograficamente por divisores de água, que coleta água das chuvas, para o seu canal principal (rio principal), através da captação dos afluentes e do escoamento superficial. Porém, não só por meio do escoamento superficial, mas também, do subterrâneo, através do lençol freático. A drenagem da bacia, converge do ponto mais alto, ao ponto mais baixo, se unificando através do rio principal em direção ao exutório, que é a foz.

Segundo Borsato \& Martoni (2004, apud Teodoro et al., 2007, p. 140) bacia hidrográfica é:

Definida como uma área limitada por um divisor de águas, que a separa das bacias adjacentes e que serve de captação natural da água de precipitação 
através de superfícies vertentes. Por meio de uma rede de drenagem, formada por cursos d'água, ela faz convergir os escoamentos para a seção do exutório, seu único ponto de saída.

Já para Tucci (1997), bacia hidrográfica pode ser entendida como uma área que capta água das precipitações e canaliza em direção ao exutório, sendo delimitada fronteiristicamente por divisores de águas, que separam uma bacia de outra.

Segundo a ANA (Agência Nacional de Águas), órgão brasileiro responsável pelos estudos e gerenciamento das águas:

Bacia hidrográfica é a região compreendida por um território e por diversos cursos d'água. Da chuva que cai no interior da bacia, parte escoa pela superfície e parte infiltra no solo. A água superficial escoa até um curso d'água (rio principal) ou um sistema conectado de cursos d'água afluentes; essas águas, normalmente, são descarregadas por meio de uma única foz (ou exutório) localizada no ponto mais baixo da região. Da parte infiltrada, uma parcela escoa para os leitos dos rios, outra parcela é evaporada por meio da transpiração da vegetação e outra é armazenada no subsolo compondo os aquíferos subterrâneos (ANA, 2011).

Em concordância com Christofoletti (1980), a quantidade de água recebida pela bacia hidrográfica irá depender das variáveis precipitação, evaporação, infiltração, escoamento, entre outras. E a rede da bacia, constituída pelo rio principal e seus afluentes, está susceptível a interferências naturais e antrópicas, ou seja, um rio, por exemplo, é reflexo da bacia na qual ele compõe.

A bacia hidrográfica tem um caráter integrador, e muitos estudiosos chegam a dizer que a mesma é a unidade mais apropriada para desenvolvimento de estudos ambientais e gerenciamento de recursos naturais para o desenvolvimento humano. Segundo Tundisi (2003, p. 107), a bacia hidrográfica "tem certas características essenciais que a torna uma unidade muito bem caracterizada e permitem a integração multidisciplinar entre diferentes sistemas de gerenciamento, estudo e atividade ambiental".

A bacia hidrográfica também é utilizada como Unidade de Planejamento e Gestão por constituir um sistema natural bem delimitado geograficamente e ocorre a interação e entre os elementos nela inseridos. Segundo Lima et al. (2016) a bacia hidrográfica é escolhida como Unidade de Planejamento e Gestão, por ser de fácil caracterização e por garantir ser uma área de análise integrada de recursos, em especial os recursos hídricos.

De acordo com Botelho e Silva (2014, apud Braz, 2017, p. 40) "A bacia hidrográfica é entendida como célula básica de análise ambiental e permite 
conhecer e avaliar seus diversos componentes e os processos de interações que nela ocorrem".

\section{Análise da Qualidade da Água da Bacia Hidrográfica}

Através da análise da qualidade da água é possível descobrir quais as características químicas, físicas e biológicas da mesma, e detectar se há contaminação ou não. Se estiver contaminada, qual o grau de contaminação e quais os elementos contaminantes. Quando apontado problemas de contaminação na composição da água, a tarefa é encontrar qual a origem dessa contaminação e uma possível solução. Para Souza \& Gastaldini (2014, p. 264):

O comportamento da qualidade da água reflete as condições ambientais da bacia hidrográfica, sendo assim, conhecer as características de qualidade da água amplia o conhecimento ecológico do ecossistema e possibilita detectar alterações provenientes da atividade humana.

Portanto, por meio da análise da qualidade da água, faz-se um diagnóstico preciso sobre a situação das amostras coletadas, o que pode indicar por consequência, o estado em que se encontra o corpo hídrico da qual foram extraídas as amostras.

O termo "qualidade de água" não trata apenas o estado de pureza da mesma, mas sim às características físicas, químicas e biológicas e, dependendo destas características, são determinados diversos destinos para a água. A qualidade da água de um determinado recurso hídrico é avaliada dependendo das substâncias presentes na água, para isso denominada de parâmetros de qualidade da água. (GLORIA, HORN E HILGEMANN, 2017, p. 105).

Dessa forma, com o conhecimento da qualidade da água de um determinado corpo hídrico é possível direcionar qual o tipo de uso mais adequado para a mesma.

Os parâmetros analisados nessa pesquisa, obtidos em campo são descritos abaixo.

Segundo Mendes et al. (2012, p. 439 ) "O oxigênio dissolvido OD é um gás solúvel em água" e de acordo com Araújo et. al. (2004, apud Mendes et al., 2012, p. 439 ) "o OD pode ser utilizado como indicador de qualidade das águas superficiais, pois a proliferação bacteriológica depende diretamente de suas concentrações, constituindo de metodologia de rápida análise, passível de realização no campo".

Nas palavras de Mendes et al. (2012, p.440):

A condutividade expressa a capacidade de condução de corrente elétrica de sais dissolvidos e ionizados presentes numa água, pode ser utilizada como parâmetro de avaliação de qualidade. A turbidez é a alteração da penetração da luz provocada por partículas em suspensão, como bactérias, 
argilas e silte ou fontes de poluição que lançam materiais finos e outras substâncias na água. $\mathrm{O}$ pH apresenta a acidez ou a basicidade das águas, que podem ter origens em fatores naturais do terreno ou resultantes de poluentes dissolvidos na água.

Segundo Melo, Nascimento e Pinto (2014, p.17) "[...] o potencial de oxidação de redução das soluções está relacionado com a perda e o recebimento dos elétrons de uma solução". Quando uma solução é classificada como oxidada, significa que perdeu elétrons e quando uma solução ganha elétrons, identifica-se a sua redução. Quanto mais oxidada, maior será sua capacidade elétrica.

Os Totais de Sólidos Dissolvidos (TDS) corresponde ao conjunto de todas as substâncias orgânicas e inorgânicas contidas num líquido sob formas moleculares, ionizadas ou microgranulares (MELO; NASCIMENTO e PINTO, 2014, p. 17). Este é usado como determinante da qualidade da água, porque avalia o peso total dos constituintes minerais, como carbonato, sódio e íons orgânicos presentes na água, por unidade de volume, sendo que esses minerais são essenciais para a vida aquática, porém, o excesso deles pode ser prejudicial (MELO; NASCIMENTO e PINTO, 2014, p. 17).

Segundo Pinto (1998, apud Mendes et al., 2012, p.440) "A temperatura do ar e da água influencia nos processos biológicos, reações químicas e bioquímicas que ocorrem na água e também outros processos como solubilidade dos gases dissolvidos, além de acentuar a sensação de sabor e odor".

Quanto maior a temperatura menor a concentração de oxigênio dissolvido $(\mathrm{OD})$, e um aumento no número de reações biológicas e químicas. Essas reações consomem o OD. O sal acelera o processo de oxirredução (ORP) que por sua vez aumenta a condutividade elétrica (CE) e pode aumentar a turbidez.

O turbilhonamento da água gera três processos: dissolução mecânica, na qual haverá aumento de material em suspensão que pode acarretar em um aumento na turbidez; reação química; e o aumento da temperatura que facilita a dissolução da matéria orgânica.

\section{Uso da Terra e sua Influência na Qualidade da Água}

Identificar o uso da terra é de grande relevância para estudo direcionados a bacia hidrográfica e a qualidade da água, pois o mesmo interfere diretamente em suas características naturais, nos seus aspectos físicos, químicos e biológicos.

De acordo com o IBGE, o uso da terra pode ser entendido, como um conjunto de informações referentes à classificação dos tipos de uso da terra na superfície 
terrestre. A partir dele podemos analisar além do uso da terra, como também os processos de ocupação, e as alterações ocorridas em um determinado espaço de tempo.

Segundo Filho, Dutra e Ceruti (2012), a alteração da qualidade da água não tem suas causas ligadas apenas no desenvolvimento industrial e no crescimento urbano, mas também no desmatamento e na forma como os agricultores utilizam suas terras. Sendo assim, identificar os usos da terra presente na área de estudo, tem como objetivo nos auxiliar a identificar as possíveis causas de degradação que afetam diretamente a qualidade da água.

\section{Procedimentos metodológicos}

A metodologia foi dividida em três etapas. A primeira etapa trata dos trabalhos realizados em laboratório e leituras dirigidas; a segunda etapa consiste ao Geoprocessamento e Geotecnologias aplicadas a qualidade da água e a última etapa refere-se a análise e enquadramento da qualidade física química das águas superficiais da BHCO.

\section{Etapa 1 - Trabalhos de Gabinete e Leituras Direcionadas}

Os trabalhos iniciais resumem-se em levantamentos bibliográficos direcionados aos temas abordados na fundamentação teórica, sendo eles, Bacia Hidrográfica, Análise da qualidade da Água em Bacias Hidrográficas, Uso da terra e Geoprocessamento e Geotecnologias aplicados a qualidade da Água.

Para esta etapa os livros e artigos específicos aos temas foram fundamentais para o direcionamento da pesquisa e a compreensão dos temas abordados, além de auxiliar no debate teórico-metodológico da execução deste trabalho.

A escolha da área de estudo ocorreu, após o trabalho de campo realizado na disciplina de Geotecnologias aplicadas ao planejamento e gestão de águas, ministrada no Programa de Pós-Graduação em Geografia na Universidade Federal de Mato Grosso do Sul, campus de Três Lagoas (PPGGEO/ UFMS/ CPTL).

Durante o trabalho de campo visitou-se diferentes pontos da Bacia Hidrográfica do Córrego da Onça no Município de Três Lagoas - MS. Entre os pontos visitados, o complexo das Lagoas despertou maior interesse neste sentido, a análise proposta será conduzida aos problemas ambientais, relacionando-os a qualidade da água. Este complexo é composto por três lagoas, que se localizam 
dentro do perímetro urbano do município, cada uma das três lagoas apresentam diferentes características e diferentes tipos de uso pela população local.

O complexo das três lagoas é responsável por influenciar no nome do município, além de estar diretamente ligado ao processo de desenvolvimento do perímetro urbano. O encanto pela beleza natural das três lagoas foi o que atraiu os primeiros moradores para a região, e foi no final do século XIX, que Antônio Trajano dos Santos constrói sua residência ao lado da terceira lagoa (Levorato, 1999). Devido a sua beleza natural, as lagoas sempre foram pontos de paradas para contemplação. Segundo Levorato (1999, p. 52) "A lagoa maior é o principal patrimônio de nossa terra, possuidor de um significativo valor cultural, estético, histórico, turístico e paisagístico para o nosso povo."

\section{- Etapa 2 - Geoprocessamento e Geotecnologias Aplicados a Qualidade da Água}

O estudo do espaço geográfico requer do pesquisador um conjunto de conhecimentos e informações necessárias para analisar e entender os diferentes fenômenos que ocorrem na superfície terrestre. Neste sentido, utilizar - se das tecnologias como ferramenta de auxilio nas pesquisas, nos proporcionam uma melhor concepção do espaço geográfico e de seus fenômenos.

De acordo com Fitz (2008), os estudos do espaço geográfico exigem uma série de informações e conhecimentos que podem ser compreendidos de maneira mais rápida e eficaz com o uso das novas tecnologias. Sendo assim, "[...] as geotecnologias tendem a ocupar um lugar de destaque em virtude de sua funcionalidade (FITZ, 2008, p.11)."

O uso do Geoprocessamento e das Geotecnologias aplicadas ao estudo da qualidade da água, possibilita diferentes análises em diferentes períodos do tempo, além de proporcionar uma visão espacial ampla da área de estudo. A partir deste entendimento é possível analisar diferentes problemas ambientais em diferentes temporalidades. No presente artigo utilizou-se do Geoprocessamento para analisar os diferentes usos da terra nas proximidades das lagoas.

Para a elaboração dos mapas foi necessária a organização dos dados, utilizando-se de dados secundários. Os dados foram adquiridos no site do Instituto Brasileiro de Geografia e Estatísticas - IBGE, sendo eles: no formato Shapefiles e 
imagens do satélite Landsat 8. Para a elaboração dos mapas, utilizamos os softwares ArcMap 10.6.1, Spring 5.4.3 e o Google Earth Pro.

- Etapa 2.1 - Elaboração do Mapa de Localização do Município, Localização das três lagoas e Localização dos pontos de coleta

Nesta etapa elaborou-se três mapas: um com a localização do município de Três Lagoas (Mapa 1), contendo os limites municipais, um contendo a localização das três lagoas (Mapa 2), e outro com a localização dos pontos de mensuração das amostras (Mapa 3).

Para elaboração desses mapas de localização, utilizou-se de dados secundários adquiridos na plataforma digital do IBGE. Os dados utilizados foram: no formato Shapefile municipal, Shapefile das unidades federativas e Shapefiles de rodovias federais. No mapa de localização das três lagoas e de localização dos pontos de coleta, também utilizou-se imagens já existentes e disponibilizadas no software do ArcMap 10.6.1.

Após adquirir os dados secundários, utilizou-se o software ArcMap 10.6.1, para a organização dos dados. O layout utilizado, em ambos os mapas segue a mesma estrutura de organização.

Mapa 3 - Mapa de Localização dos Pontos de Coletas

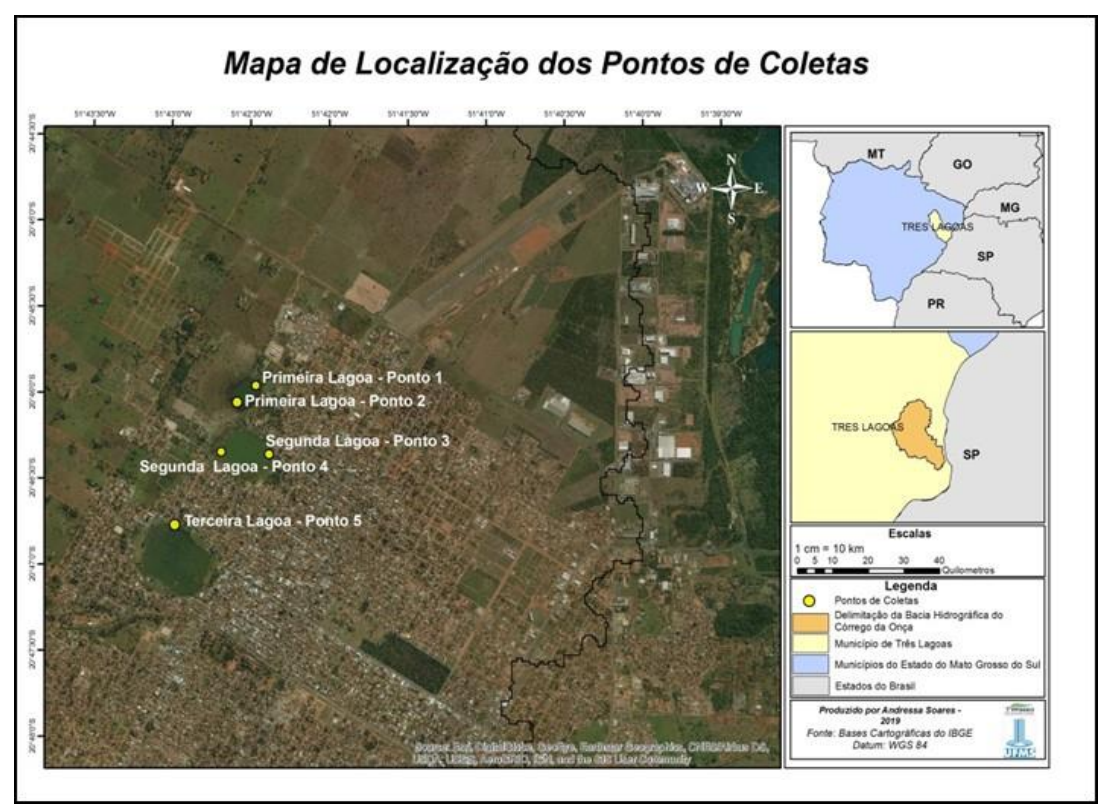

Fonte: Dos autores, 2019.

Como apresentado no Quadro 1, pode-se observar os pontos de coleta espacializados no Mapa 3.

Quadro 1 - Coordenadas Geográficas dos pontos de mensuração das amostras da água na BHCO. 


\begin{tabular}{|c|c|c|}
\hline \multirow{2}{*}{\multicolumn{2}{|c|}{$\begin{array}{l}\text { Coordenadas Geográficas } \\
\text { Primeira Lagoa - Ponto } 1\end{array}$}} & \multirow[t]{2}{*}{ Figuras } \\
\hline & & \\
\hline Latitude & Longitude & \\
\hline $20^{\circ} 45^{\prime} 58.75^{\prime \prime} \mathrm{S}$ & $51^{\circ} 42^{\prime 2} 27.85^{\prime \prime} \mathrm{O}$ & \\
\hline \multicolumn{2}{|c|}{ Primeira Lagoa - Ponto 2} & \multirow{3}{*}{$-119=11$} \\
\hline Latitude & Longitude & \\
\hline $20^{\circ} 46^{\prime} 3.89^{\prime \prime} \mathrm{S}$ & $51^{\circ} 42^{\prime} 32.05^{\prime \prime} \mathrm{O}$ & \\
\hline \multicolumn{2}{|c|}{ Segunda Lagoa - Ponto 3} & \multirow{3}{*}{$\begin{array}{l}1 \text { a } \\
\text { ala }\end{array}$} \\
\hline Latitude & Longitude & \\
\hline $20^{\circ} 46^{\prime} 20.98^{\prime \prime} \mathrm{S}$ & $51^{\circ} 42^{\prime} 22.47^{\prime \prime} \mathrm{O}$ & \\
\hline \multicolumn{2}{|c|}{ Segunda Lagoa - Ponto 4} & \multirow{3}{*}{$T^{2}$} \\
\hline Latitude & Longitude & \\
\hline $20^{\circ} 46 ' 20.91 " \mathrm{~S}$ & $51^{\circ} 42^{\prime} 41.54^{\prime \prime} \mathrm{O}$ & \\
\hline \multicolumn{2}{|c|}{ Terceira Lagoa - Ponto 5} & \multirow{2}{*}{$+1, \frac{9}{1}-2 x$} \\
\hline $20^{\circ} 46^{\prime} 46.57^{\prime \prime} \mathrm{S}$ & $51^{\circ} 42^{\prime} 59.39^{\prime \prime} \mathrm{O}$ & \\
\hline
\end{tabular}

Fonte: Dos autores, 2019.

- Etapa 2.2 - Elaboração do Mapa de Uso da Terra da Bacia Hidrográfica do Córrego da Onça

O mapa de uso da terra da Bacia Hidrográfica do Córrego da Onça, foi elaborado a partir da utilização de três softwares: o Spring 5.4.3, para o processamento das imagens do satélite Landsat 8, o ArcMap 10.6.1 para a elaboração do layout e o Google EarthPro como ferramenta auxiliar na compreensão da imagem, após a realização da segmentação no Spring 5.4.3.

Para elaboração do mapa utilizou-se imagens do satélite Landsat 8 com as bandas e as composições coloridas R5, G4, B3. Esta composição permitiu visualizar de maneira mais clara os limites entre solo exposto, água e a vegetação. 
Com a utilização das técnicas de Geoprocessamento analisou-se o uso da terra identificando seus usos e como os mesmos influenciaram na qualidade da água das três lagoas.

Como referência na elaboração deste mapa, utilizou-se o Manual Técnico de Uso e Ocupação da Terra, $2^{\circ}$ edição. Na etapa de classificação, adotou-se como critérios as cores e classes determinadas. As classes e subclasses estão descritas no Quadro 2.

Quadro 2 - Classes e subclasses para o mapeamento temático.

\begin{tabular}{|l|r|l|}
\hline \multicolumn{1}{|c|}{ Nível I } & \multicolumn{2}{|c|}{ Nível II } \\
\hline 1. Áreas Antrópicas Não Agrícolas & 1.1 & Área Urbanizada \\
\hline \multirow{2}{*}{ 2. Áreas Antrópicas Agrícolas } & 2.3 & Pastagem \\
\cline { 2 - 4 } & 2.4 & Silvicultura \\
\hline 3. Áreas de vegetação Natural & 3.1 & Floresta \\
\hline 4. Água & 4.1 & Corpo d'Água Continental \\
\hline
\end{tabular}

Fonte: Manual do Uso da terra, 2006, p.149 adaptado pelos autores (2019).

A utilização deste manual é fundamental na elaboração de trabalhos científicos, pois estabeleceu-se um padrão de símbolos, cores e nomenclaturas para cada área classificada.

\section{- Etapa 3 - Análise e Enquadramento da Qualidade Física Química das Águas Superficiais da BHCO}

Nesta etapa realizou-se a análise da qualidade da água a partir da mensuração com o Horiba U50 dos parâmetros oxigênio dissolvido - OD, pH, condutividade elétrica - CE, turbidez, potencial redox - ORP, salinidade e temperaturas do ar e da água.

Foram selecionados 5 pontos amostrais para a mensuração da qualidade físico química das águas da $\mathrm{BHCO}$, enfatizando seu alto curso, onde alojam-se as três lagoas urbanas (Quadro 1).

Com base na Tabela 1, foi possível analisar e classificar os dados obtidos através das mensurações de campo. Para confrontar os dados dos parâmetros analisados utilizou as classes estabelecidas na Resolução CONAMA 357 de 2005 adaptada por Pinto et al. (2009) (Tabela 1) e (Quadro 3).

Tabela 1 - Limites dos parâmetros para enquadramento nas Classes das Águas Doces no Brasil.

\begin{tabular}{l|l}
\hline Classes & Limites para o Enquadramento \\
\hline \multirow{3}{*}{ Especial } & $\begin{array}{l}\text { Nas águas de classe especial deverão ser mantidas as condições naturais do } \\
\text { corpo de água. } \\
\text { OD }+10,0 \mathrm{mg} / \mathrm{L}\end{array}$ \\
\hline
\end{tabular}




\begin{tabular}{|c|c|}
\hline & $\begin{array}{l}\text { pH } 6,0 \text { a } 9,0 \\
\text { Turbidez } 0 \text { até } 20 \text { NTU } \\
\text { Condutividade Elétrica até } 50 \mathrm{uS} / \mathrm{cm} \\
\text { TDS } 0 \text { a } 200 \mathrm{mg} / \mathrm{L} \\
\text { ORP } 0 \text { a } 300 \mathrm{mV}\end{array}$ \\
\hline I & $\begin{array}{l}\text { OD } 10 \text { a } 6 \mathrm{mg} / \mathrm{L} \\
\text { pH } 6,0 \text { a } 9,0 \\
\text { Turbidez } 20 \text { até } 40 \mathrm{NTU} \\
\text { Condutividade Elétrica } 50 \text { até } 75 \mathrm{uS} / \mathrm{cm} \\
\text { TDS } 200 \text { a } 300 \mathrm{mg} / \mathrm{L} \\
\text { ORP } 300 \text { a } 400 \mathrm{mV}\end{array}$ \\
\hline II & $\begin{array}{l}\text { OD } 6 \text { a } 5 \mathrm{mg} / \mathrm{L} \\
\text { pH } 6,0 \text { a } 9,0 \\
\text { Turbidez } 40 \text { até } 70 \mathrm{NTU} \\
\text { Condutividade Elétrica } 75 \text { até } 100 \mathrm{uS} / \mathrm{cm} \\
\text { TDS } 300 \text { a } 400 \mathrm{mg} / \mathrm{L} \\
\text { ORP } 400 \text { a } 500 \mathrm{mV}\end{array}$ \\
\hline III & $\begin{array}{l}\text { OD } 5 \text { a } 4 \mathrm{mg} / \mathrm{L} \\
\text { pH } 6,0 \text { a } 9,0 \\
\text { Turbidez } 70 \text { até } 100 \mathrm{NTU} \\
\text { Condutividade Elétrica } 100 \text { até } 150 \mathrm{uS} / \mathrm{cm} \\
\text { TDS } 400 \text { a } 500 \mathrm{mg} / \mathrm{L} \\
\text { ORP } 500 \text { a } 600 \mathrm{mV}\end{array}$ \\
\hline IV & $\begin{array}{l}\text { OD }-4 \mathrm{mg} / \mathrm{L} \\
\text { pH } 6,0 \text { a } 9,0 \\
\text { Turbidez acima de } 100 \mathrm{NTU} \\
\text { Condutividade Elétrica }+150 \mathrm{uS} / \mathrm{cm} \\
\text { TDS }+500 \mathrm{mg} / \mathrm{L} \\
\text { ORP }+600 \mathrm{mV}\end{array}$ \\
\hline
\end{tabular}

Fonte: Pinto et al. (2009) adaptado da Resolução ํo. 357/05 do CONAMA.

Para a classificação dos tipos de usos da água (Quadro 3), foram utilizados os valores dos limites de enquadramento conforme Tabela 1 criados pela Resolução n. CONAMA 357/05 e adaptados por Pinto et al. (2009). A classificação indica, além da qualidade da água e de suas limitações de uso, as ações que devem ser tomadas na melhoria da qualidade de cada uma das três lagoas.

Quadro 3 - Principais Classes de Limitações de Uso das Águas Doces no Brasil.

\begin{tabular}{|l|l|}
\hline Classes & Principais Usos \\
(cor laranja) & $\begin{array}{l}\text { Consumo humano com desinfecção; Preservação de equilíbrio natural das } \\
\text { comunidades aquáticas; Preservação dos ambientes aquáticos em unidades de } \\
\text { conservação de proteção integral. }\end{array}$ \\
\hline $\begin{array}{l}\text { (cor verde- } \\
\text { claro) }\end{array}$ & $\begin{array}{l}\text { Consumo humano, após tratamento simplificado; Proteção das comunidades } \\
\text { aquáticas; Recreação de contato primário (natação, esqui aquático e mergulho) } \\
\text { Resolução CONAMA n. 274, de 2000; Irrigação de hortaliças que são consumidas } \\
\text { cruas e de frutas que se desenvolvam rentes ao solo e que sejam ingeridas sem } \\
\text { remoção de películas e à proteção das comunidades aquáticas em Terras } \\
\text { Indígenas. }\end{array}$ \\
\hline $\begin{array}{l}\text { II } \\
\text { (cor verde) }\end{array}$ & $\begin{array}{l}\text { Abastecimento para consumo humano, após tratamento convencional, à proteçãó } \\
\text { das comunidades aquáticas, à recreação de contato primário, tais como natação, } \\
\text { esqui aquático e mergulho, Resolução CONAMA n. 274, de 2000, à irrigação de } \\
\text { hortaliças, plantas frutíferas e de parques, jardins, campos de esporte e lazer, com } \\
\text { os quais o público possa vir a ter contato direto e à aquicultura e à atividade de } \\
\text { pesca. }\end{array}$ \\
\hline $\begin{array}{l}\text { III } \\
\text { (cor azul- } \\
\text { claro) }\end{array}$ & $\begin{array}{l}\text { Abastecimento para consumo humano, após tratamento convencional ou ou } \\
\text { amançado, à irrigação de culturas arbóreas, cerealíferas e forrageiras, à pesca } \\
\text { amadora, à recreação de contato secundário e à dessedentação de animais. }\end{array}$ \\
\hline
\end{tabular}




\begin{tabular}{|l|l|}
\hline $\begin{array}{l}\text { IV } \\
\text { (cor } \\
\text { vermelho) }\end{array}$ & Navegação e à harmonia paisagística \\
\hline
\end{tabular}

Fonte: Resolução nํ. 357 do CONAMA de 17/03/2005.

\section{Resultados e discussões}

\section{Análise do Uso da Terra da BHCO.}

Tendo como base as informações obtidas a partir do Mapa 4, calculou-se o tamanho da área total e das classes de uso da terra da $\mathrm{BHCO}$, em $\mathrm{Km}^{2}$ e em porcentagem (Quadro 4).

Mapa 4 - Mapa de Uso da Terra da Bacia Hidrográfica do Córrego da Onça no Município de Três Lagoas - MS

\section{USO DA TERRA DA BACIA HIDROGRÁFICA DO CÓRREGO DA ONÇA NO MUNICÍPIO DE TRÊS LAGOAS - MS}

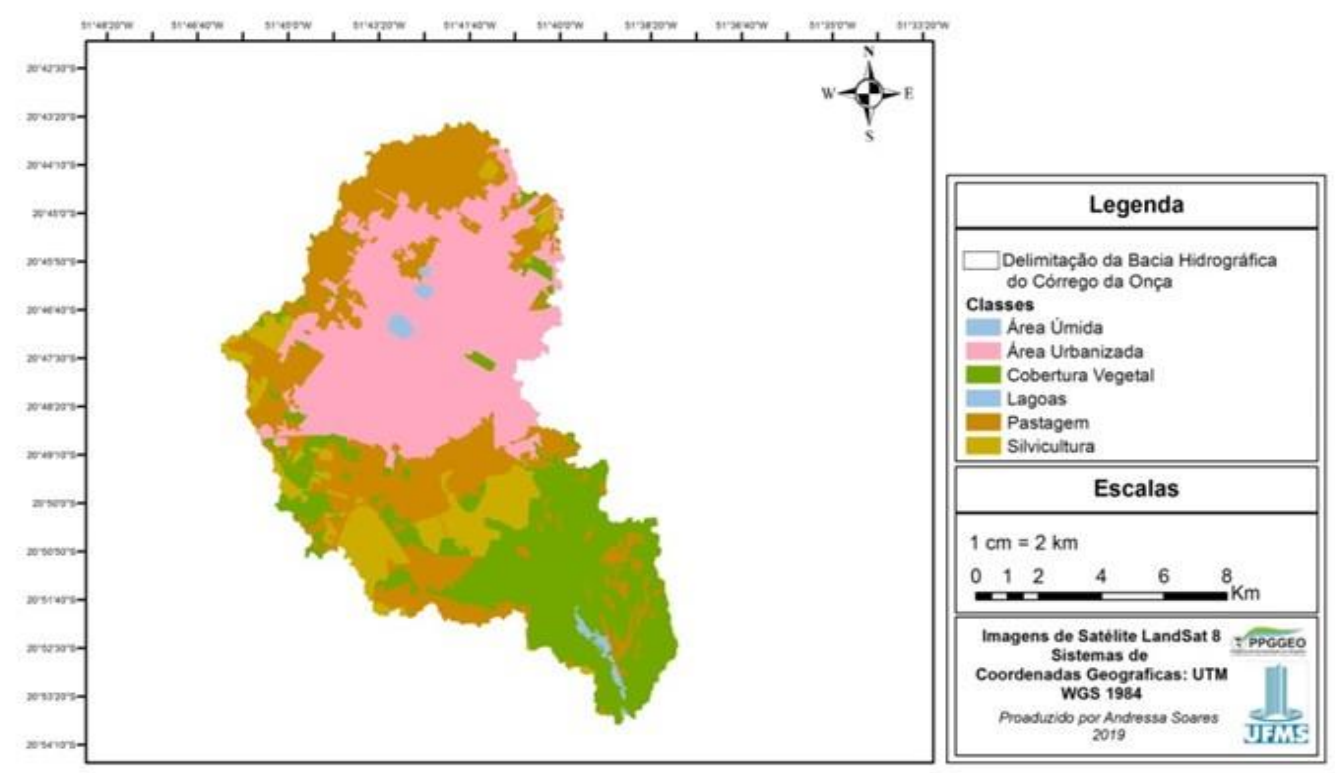

Fonte: Dos autores, 2019.

De acordo com o Quadro 4, a área total da BHCO é de $143,35 \mathrm{Km}^{2}$. É notório a soberania da Área Urbanizada na BHCO, por apresentar $34,85 \%$ da área da bacia. Em seguida vem a Pastagem com $29,99 \%$ de uso do solo. A cobertura vegetal está presente em $24,95 \%$ da área. Posteriormente vem a atividade de Silvicultura, com 9,13\%, as Lagoas, com 0,78\% e por último a Área Úmida, com $0,51 \%$ da área.

Quadro 4 - Uso da Terra na BHCO

\begin{tabular}{|l|l|l|}
\hline Classes & $\mathbf{K m}^{\mathbf{2}}$ & Porcentagem (\%) \\
\hline Área Urbanizada & 49,96 & 34,85 \\
\hline Área Umida & 0,74 & 0,51 \\
\hline Cobertura Vegetal & 35,78 & 24,95 \\
\hline Lagoas & 0,78 & 0,54 \\
\hline
\end{tabular}




\begin{tabular}{|l|l|l|}
\hline Pastagem & 43,00 & 29,99 \\
\hline Silvicultura & 13,09 & 9,13 \\
\hline Total: & 143,35 & 100 \\
\hline
\end{tabular}

Fonte: Dos autores, 2019.

Ao observar o Mapa 4 nota-se que a maior parte da BHCO corresponde a área urbana. As três lagoas encontram-se dentro dessa área e, portanto, sofrem diretamente alterações antrópicas, como visto anteriormente. No entanto, cada uma das lagoas, está exposta a diferentes impactos.

\section{Análise da Qualidade das Águas Superficiais das Lagoas da BHCO.}

No Quadro 5, apresenta-se os parâmetros da qualidade da água que foram mensurados de acordo com seus valores. Verifica-se que a salinidade permanece em zero em todos os cinco pontos de coleta. Quanto a velocidade da água, nos Pontos 4 e 5 ela não foi contabilizada, por conta de erros no aparelho medidor. A maior temperatura do ar encontrada foi a do ponto 5 (Terceira Lagoa), provavelmente justificada pela ausência de vegetação, malha asfáltica e circulação de veículos no seu entorno. Nesse mesmo ponto foi identificada a maior Turbidez em comparação aos outros quatro pontos, com 20,1 NTU ou Unidade Nefelométrica de Turbidez. Já a maior temperatura da água foi no ponto 4 (Segunda Lagoa).

O potencial de oxidação-redução (redox) ou ORP no ponto 3 (Segunda Lagoa) de $396 \mathrm{mV}$ ou milivolts é maior que nos demais pontos. A condutividade elétrica tem o valor maior, de $0,045 \mathrm{uS} / \mathrm{cm}$ ou microsiemens, no ponto 5 . O oxigênio dissolvido (OD) de 10,85 mg/L ou miligramas por litro, supera os outros pontos. Os sólidos totais dissolvidos (TDS), foram encontrados em maior quantidade no ponto 5 , com $26 \mathrm{mg} / \mathrm{L}$.

Quadro 5 - Qualidade da Água Superficiais das Lagos do Alto Curso da BHCO, Três Lagoas/MS, no Inverno de 2019.

\begin{tabular}{|c|c|c|c|c|c|}
\hline \multirow{2}{*}{$\frac{\text { LOCAL }}{\text { Pontos }}$} & \multicolumn{2}{|c|}{ Primeira Lagoa } & \multicolumn{2}{|c|}{ Segunda Lagoa } & \multirow{2}{*}{\begin{tabular}{|l} 
Terceira Lagoa \\
Ponto5 \\
\end{tabular}} \\
\hline & Ponto1 & Ponto2 & Ponto3 & Ponto4 & \\
\hline Horário & 08:00 & 08:39 & 09:15 & 09:38 & $10: 10$ \\
\hline Dia de coleta & 07/jun & 07/jun & 07/jun & 07/jun & 07/jun \\
\hline Temp. do ar (Cํㅡ) & 22,4 & 22 & 23,63 & 23,65 & 24,44 \\
\hline Temp. da água $\left(\mathrm{C}^{\circ}\right)$ & 23,07 & 22,95 & 24,05 & 24,6 & 23,52 \\
\hline $\mathrm{ORP}(\mathrm{mV})$ & 335 & 376 & 396 & 379 & 385 \\
\hline CE (uS/cm) & 0,014 & 0,012 & 0,022 & 0,022 & 0,045 \\
\hline Turbidez (NTU) & 10 & 12 & 14 & 10,1 & 20,1 \\
\hline $\mathrm{OD}(\mathrm{mg} / \mathrm{L})$ & 7,36 & 10,57 & 8,9 & 10,85 & 6,22 \\
\hline TDS (mg/L) & 0,009 & 0,008 & 15 & 0,014 & 26 \\
\hline
\end{tabular}




\begin{tabular}{|l|r|r|r|r|r|} 
Salinidade (\%) & 0 & 0 & 0 & 0 & 0 \\
\hline Velocidade $(\mathrm{m} / \mathrm{s})$ & 0,02 & 0,03 & 0,6 & -17 & 317 \\
\hline Altitude $(\mathrm{m})$ & 316 & 317 & 318 & 315 & 323 \\
\hline
\end{tabular}

Fonte: Dos autores, 2019.

No Quadro 6 encontram-se o enquadramento dos parâmetros da qualidade da água de cada ponto de coleta segundo Pinto et al. (2009) adaptado da Resolução no. 357/05 do CONAMA.

Quadro 6 - Enquadramento CONAMA dos Parâmetros da Qualidade da Água das Lagoas da BHCO, Três Lagoas/MS, no Inverno de 2019.

\begin{tabular}{|c|c|c|c|c|c|}
\hline \multirow{2}{*}{$\begin{array}{l}\text { LOCAL } \\
\text { Parâmetros }\end{array}$} & \multicolumn{2}{|c|}{ Primeira Lagoa } & \multicolumn{2}{|c|}{ Segunda Lagoa } & \multirow{2}{*}{$\begin{array}{c}\text { Terceira Lagoa } \\
\text { Ponto5 }\end{array}$} \\
\hline & Ponto1 & Ponto2 & Ponto3 & Ponto4 & \\
\hline ORP $(\mathrm{mV})$ & & & Classe II & & \\
\hline CE (uS/cm) & Classe especial & Classe especial & Classe IV & Classe especial & Classe especia \\
\hline Turbidez (NTU) & Classe especial & Classe especial & Classe especial & Classe especial & \\
\hline$O D(m g / L)$ & & Classe especial & & Classe especial & \\
\hline TDS (mg/L) & Classe especial & Classe especial & Classe especial & Classe especial & Classe especia \\
\hline Salinidade (\%) & água doce & água doce & água doce & água doce & água doce \\
\hline Classficação geral & Classe I & Classe especial & Classe I & Classe especial & Classe $\mid$ \\
\hline
\end{tabular}

De acordo com a observação do Quadro 6 é possível afirmar que a Classe 1 se sobressai na Classificação geral, especificamente nos pontos de coleta 1, 3 e 5, ou seja, um ponto em cada uma das três lagoas. Segundo a Resolução do CONAMA no. 357/05: A Classe 1, determina consumo humano após tratamento simplificado. Nos pontos 2 e 4, a classificação é Classe Especial, o que significa "Consumo humano com desinfecção" (Resolução $n^{\circ} .357$ do CONAMA de 17/03/2005).

Considerando as análises, a primeira lagoa está em uma área com fragmentos de pastagem, e de acordo com a classificação no Quadro 6, ela está enquadrada na Classe 1 e Classe Especial, ou seja, o consumo humano pode ser realizado, mediante tratamento simples da água. Acredita-se que a Classe 1 pode ser resultado de vários fatores, tais como despejo de lixo doméstico e/ ou escoamento da água da chuva carreada de sedimentos.

$\mathrm{Na}$ segunda lagoa, há também área de pastagem, porém reduzida. A classificação fica nas classes 1 e Especial (assim como a primeira lagoa), e, portanto, sua água deve ter o mesmo tratamento da primeira.

$\mathrm{Na}$ terceira lagoa, o único ponto de coleta, se enquadra na Classe 1, porém os riscos mais graves de poluição, se concentram na primeira e segunda lagoa. 
Pois, além de ser completamente antropizada (com prédios, pista de caminhada, no seu entorno), ela ainda sofre com o assoreamento, causado em épocas de cheias e inundações das vias ao seu redor. Outro fator que influencia na mudança da qualidade da água é a presença de fezes de capivaras e outros animais, que se encontram em grande número no local.

Entende-se que as três lagoas estão suscetíveis a ficarem inadequadas à sobrevivência das espécies animais e vegetais que ali se encontram, como também inapropriadas ao consumo humano.

\section{Considerações finais}

A qualidade da água é resultado de um conjunto de fatores naturais e/ou antrópicos e está diretamente relacionada ao uso da terra na Bacia Hidrográfica. $O$ tipo de uso da terra interfere diretamente nas características naturais da água podendo provocar a degradação da água, em casos de alto índice de urbanização e despejo de resíduos sólidos e dejetos na água. Portanto, devem ser definidos usos adequados que visam a preservação ambiental das três lagoas.

No entanto, nem sempre o uso da terra é planejado de maneira que não afete a qualidade da água. Pois, o crescimento urbano desordenando e sem planejamento no Monumento Natural das Lagoas, resultou em áreas fortemente degradadas, afetando diretamente os recursos naturais. É importante destacar que planejar e controlar o uso da terra são requisitos fundamentais e indispensáveis no processo de conservação dos recursos naturais.

A partir dos resultados dessa pesquisa, são apontadas algumas considerações a respeito da conservação do Monumento Natural das Lagoas e sugeridas ações para as autoridades competentes, que priorizam ações em prol do meio ambiente, e da população três-lagoensse.

É fato que o mal uso da terra é o principal motivo da degradação nas lagoas, resultando na poluição da área, seguida pelo assoreamento. A poluição tem origem no descarte de resíduos nas lagoas, em grande parte por moradores desinformados que residem próximo às lagoas. Uma solução para isso, seria a Prefeitura, através da Secretaria do Meio Ambiente, elaborar um projeto de Educação Ambiental, no intuito de conscientizar todos os moradores do município de que as lagoas possuem ecossistemas que mantém espécies diversas de animais e vegetais. Portanto, estas 
devem ser protegidas e conservadas, para o bem da biodiversidade, e também para o bem da população, que utiliza a água das lagoas, para pesca ou para lazer.

Outro ponto a ser destacado é a inexistência de um plano de manejo, tendo em vista, que o Conselho Gestor do Monumento Natural da Lagoas (criado pelo CNUC) tem um prazo de cinco anos para apresentá-lo. Cabe, ressaltar a importância de um plano de manejo em Unidades de Conservação. Segundo o Ministério do Meio Ambiente "Uma das ferramentas mais importantes do plano de manejo é o zoneamento da UC, que a organiza espacialmente em zonas sob diferentes graus de proteção e regras de uso.".

Portanto, o plano de manejo promove a inclusão das comunidades adjacentes a UC, contribuindo para uma implementação mais eficiente, considerando que as comunidades poderão se conscientizar visando a conservação das lagoas.

\section{Referências Bibliográficas}

AGÊNCIA NACIONAL DE ÁGUAS - ANA. O Comitê de Bacia Hidrográfica: o que é e o que faz? Cadernos de capacitação em recursos hídricos, v. 1. Agência Nacional de Águas (ANA). Brasília: SAG, 2011. 64 p.

BRASIL, Conselho Nacional do Meio Ambiente - CONAMA. Resolução n 357, de março de 2005. Estabelece classificação para as águas doces, salobras e salinas do território nacional. Diário Oficial da União: República Federativa do Brasil, Poder Executivo, DOU. № 53. Seção 1. Brasília/DF, 2005. p.23

BRAZ, Adalto Moreira. Geotecnologias aplicadas na análise das implicações entre o uso, cobertura e manejo da terra e a qualidade das águas superficiais: bacias hidrográficas dos córregos Lajeado Amarelo e Ribeirãozinho. Dissertação (Mestrado em Geografia) - UFMS/ CPTL. Três Lagoas/MS, p.287. 2017.

CAVARARO, R. Manual Técnico de Uso da Terra. Rio de Janeiro, Brasil. $2^{\circ}$ edição. Editora: Instituto Brasileiro de Geografia e Estatísticas - IBGE, 2006.

CHRISTOFOLETTI, A. Geomorfologia. 2. ed. São Paulo: Edgard Blücher. 1980. 188 p.

ESPINDULA, Neiva Luzia. Influência do uso e cobertura da Terra na qualidade da água na bacia hidrográfica do rio Bubu, município de Cariacica-ES. 2012. 69f. Trabalho de Conclusão de Curso (Bacharelado em Geografia)-Universidade Federal do Espírito Santo, Vitória, 2012.

FILHO, Antonio Conceição Paranhos et al. (Orgs.). Geotecnologias em Aplicações Ambientais. Editora UFMS, 2016.

FILHO, Paulo Costa de O.;DUTRA, Andressa Moraes; CERUTI, Fabiane Cristina. Qualidade das Águas Superficiais e o Uso da Terra: Estudo de Caso Pontual em Bacia Hidrográfica do Oeste do Paraná. FLORAM, vol. 19, n1, p.32-43, 2012.

FITZ, Paulo Roberto. Geoprocessamento sem complicação. Oficina de textos, 2008. 
GLORIA, Lucivania Pereira; HORN, Bruna Carolina; HILGEMANN, Maurício. Avaliação da qualidade da água de bacias hidrográficas através da ferramenta do Índice de Qualidade da Água-IQA. Revista Caderno Pedagógico, v. 14, n. 1, 2017.

LEVORATO, Adão Valdemir. Três Lagoas: Dama em Preto e Branco, 1918-1964. $2^{\circ}$ edição. Três Lagoas, MS: Graf Set Ltda, 1999.

LIMA, Geisiane Aparecida de; GENEROSO, Camila Marques; SANTOS, Cosme Martins dos; SILVA, Luciana Aparecida; SOUSA, Rayssa Garcia de. Bacia hidrográfica como unidade de planejamento e gestão: estudo de caso Ribeirão Isidoro. In: VII Congresso Brasileiro de Gestão Ambiental. Campina Grande, Paraíba. 2016.

MELO, Danilo Souza; NASCIMENTO, Geise Teixeira do; PINTO, André Luiz. Balneabilidade da lagoa maior, Três Lagoas-MS. Revista Eletrônica AGB-TL, v. 1, n. 19, p. 9-27, 2014.

MENDES, Alyson Marcelo Savio; BORGES, Victor Hugo Marcoviq; SOUZA, Denivaldo Ferreira de. PINTO, André Luiz. A Influência do uso e ocupação da terra na qualidade das águas superficiais da Bacia do Córrego Bom Jardim Brasilândia/MS. Periódico Eletrônico Fórum Ambiental da Alta Paulista, v. 8, n. 2, 2012.

MINISTÉRIO DO MEIO AMBIENTE. O que são UC. Disponível em: <https://www.mma.gov.br/areas-protegidas/unidades-de-conservacao/o-que-sao.html>. Acesso em 03 de fevereiro de 2020.

MINISTÉRIO DO MEIO AMBIENTE. Painel de Unidades de Conservação Brasileira. Disponível em <https://app.powerbi.com/view?r=eyJrljoiMDNmZTA5Y2ltNmFkMy00Njk2LWI4YjYtZDJINzFk OGM5NWQ4liwidCI6ljJiMjY2ZmE5LTNmOTMtNGJiMS05ODMwLTYzNDY3NTJmMDNINCIs ImMiOjF9 >. Acesso em: 26 ago. 2019.

MINISTÉRIO DO MEIO AMBIENTE. Unidades de Conservação. Disponível em: $<$ https://www.mma.gov.br/areas-protegidas/unidades-de-conservacao>. Acesso em 03 de fevereiro de 2020.

PINTO, André Luiz.; OLIVEIRA, Gustavo Henrique de.; PEREIRA, Gabrielle Alberta. Avaliação da eficiência da utilização do oxigênio dissolvido como principal indicador da qualidade das águas superficiais da Bacia do Córrego Bom Jardim, Brasilândia/MS. In:

Anais do II Seminário de Recursos Hídricos da Bacia Hidrográfica do Paraíba do Sul: Recuperação de Áreas Degradadas Serviços Ambientais e Sustentabilidade. IPABHi. Taubaté, Brasil, p. 553-560, 2009.

SOUZA, B. L. de; FRASSON, F. de S.; VIEIRA, M. F.; JESUS, S. C. da S. de; PINHO, R. G.; SILVA, R. W. de S. Estudo sobre o Córrego da Onça em Três Lagoas-MS e sua atual situação. Conexão Eletrônica, v. 15, n. 01, 2018.

SOUZA, Marielle Medeiros de; GASTALDINI, Maria do Carmo Cauduro. Avaliação da qualidade da água em bacias hidrográficas com diferentes impactos antrópicos. Eng Sanit Ambient, v. 19, n. 3, p. 263-274, 2014.

TEODORO, Valter Luiz lost et al. O conceito de bacia hidrográfica e a importância da caracterização morfométrica para o entendimento da dinâmica ambiental local. Revista Brasileira Multidisciplinar, v. 11, n. 1, p. 137-156, 2007.

TUCCI, Carlos Eduardo Morelli (Org.). Hidrologia: ciência e aplicação. 2. ed. Porto Alegre: ABRH: Editora da UFRGS, 1997.

TUNDISI, J. G. Água no século XXI: enfrentando a escassez. São Carlos: RIMA, 2003. 


\section{Notas de Autor}

\section{CONTRIBUIÇÃO DE AUTORIA}

Mário Marcio Geminiano- Concepção. Coleta de dados, Análise de dados, Elaboração do manuscrito, revisão e aprovação da versão final do trabalho

Andressa Soares- Concepção e elaboração do manuscrito. Coleta de dados Participação ativa da discussão dos resultados; Revisão e aprovação da versão final do trabalho.

André Luiz Pinto- Concepção e elaboração do manuscrito. Coleta de dados Participação ativa da discussão dos resultados; Revisão e aprovação da versão final do trabalho.

\section{FINANCIAMENTO}

Não se aplica.

CONSENTIMENTO DE USO DE IMAGEM

Não se aplica.

\section{APROVAÇÃO DE COMITÊ DE ÉTICA EM PESQUISA}

Não se aplica.

\section{CONFLITO DE INTERESSES}

Não se aplica.

\section{LICENÇA DE USO}

Este artigo está licenciado sob a Licença Creative Commons CC-BY. Com essa licença você pode compartilhar, adaptar, criar para qualquer fim, desde que atribua a autoria da obra.

\section{HISTÓRICO}

Recebido em: 19-02-2020

Aprovado em: 08-08-2020 